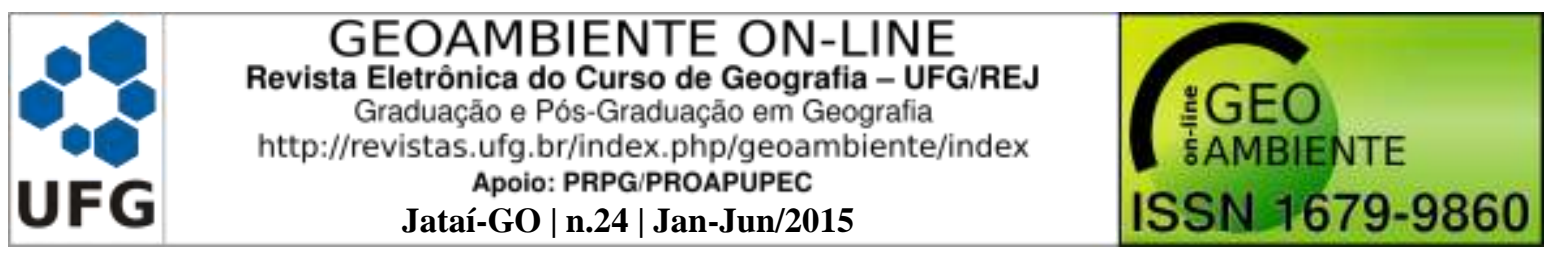

\title{
PERCEPÇÃO E CONSCIÊNCIA AMBIENTAL: UM ESTUDO EXPLORATÓRIO EM LAGES - SC
}

Tamires Liza Deboni ${ }^{\mathbf{1}}$, Gabriel Nathan Nicola Mombach ${ }^{\mathbf{1}}$, Michelle das Neves Lopes ${ }^{\mathbf{2}}$, Flávio José Simioni

1 - Universidade do Estado de Santa Catarina - UDESC, Engenheira Ambiental; tamideboni@yahoo.com.br, gabriel@mombach.ca, 2 - Universidade do Estado de Santa Catarina - UDESC, Docente do Curso de Engenharia Ambiental, michellenlopes@gmail.com, flavio.simioni@udesc.br)

Resumo: A redução dos impactos ambientais e a melhoria da qualidade de vida estão diretamente relacionadas à maior consciência ambiental e atitude da população. Com este enfoque, o objetivo deste trabalho foi avaliar a percepção e o comportamento dos residentes quanto a alguns aspectos ambientais comumente vivenciados em seus domicílios. A coleta dos dados foi realizada mediante a aplicação de questionários diretamente a 89 famílias de Lages/SC, durante o período de agosto a dezembro de 2013. Os principais resultados encontrados indicam que a preocupação e o comportamento ambientalmente corretos são mais elevados nas classes da população com maior escolaridade. Verificou-se também um desconhecimento por significativa parte da população sobre medidas colaborativas eficazes que podem ser tomadas e das consequências socioambientais de atitudes incorretas. De maneira geral, a pesquisa verificou que, embora manifestem preocupação quanto ao tema, a população ainda não incorpora ações práticas significativas no seu cotidiano, principalmente por desconhecê-las.

Palavras-chave: comportamento, percepção ambiental, impactos ambientais.

\section{ENVIRONMENTAL CONCERN AND AWARENESS: AN EXPLORATORY STUDY \\ IN LAGES - SC}

\footnotetext{
Artigo recebido para publicação em 20 de abril de 2015

Artigo aprovado para publicação em 25 de Julho de 2015
} 


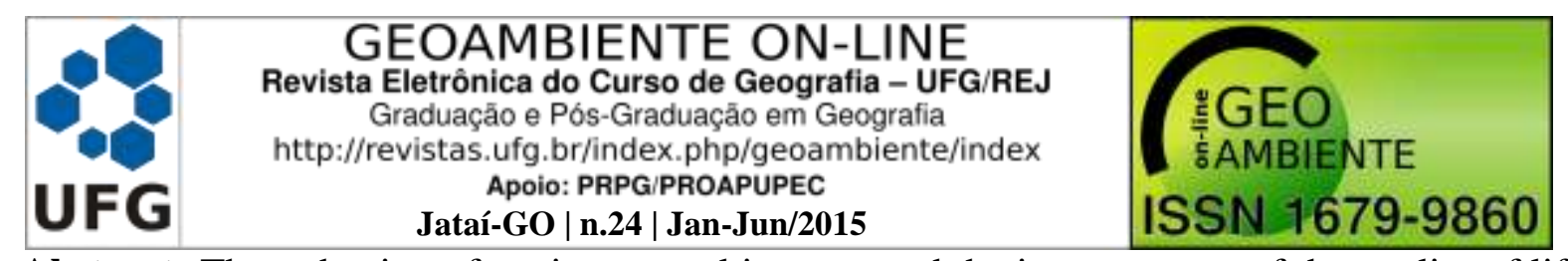

Abstract: The reduction of environmental impacts and the improvement of the quality of life are both directly related to a greater environmental awareness and attitude of the population. With this approach, this study's aim was to evaluate the residents' perception and behavior for items such as environmental aspects commonly lived by them in their homes. The data gathering was held by a survey directly applied to 89 families in Lages/SC, for the period of August to December 2013. The main results indicate that high environmental concern and behavior are connected to higher educational levels. Additionally, it was observed that there is a lack of knowledge by a significant part of the population about efficient collaborative ways that can be used and the consequences of incorrect socio-environmental attitudes. Furthermore, this survey indicates that although part of the population demonstrates concern in terms of environmental matters, these actions do not weigh in remarkably in their daily basis practices, mainly by a lack of knowledge about it.

Keywords: attitude, environmental concern, environmental impacts.

\section{PERCEPCIÓN Y CONCIENCIA AMBIENTAL: UN ESTUDIO EXPLORATORIO EN LAGES - SC}

Resumen: La reducción de los impactos ambientales y la mejoría de la calidad de vida están directamente relacionadas a la mayor conciencia ambiental y actitud de la población. Con este enfoque, el objetivo de este trabajo fue evaluar la percepción y el comportamiento de los residentes en cuanto a algunos aspectos ambientales comúnmente vivenciados en sus domicilios. La colecta de datos fue realizada mediante la aplicación de cuestionarios directamente a 89 familias de Lages/SC, durante el período de agosto a diciembre de 2013. Los principales resultados encontrados indican la preocupación y el comportamiento ambientalmente correctos son más elevados en las clases de la población con mayor escolaridad. Hay también un desconocimiento por significativa parte de la población de medidas colaborativas eficaces que pueden ser tomadas e las consecuencias socios ambientales de actitudes incorrectas. De manera general, la investigación verificó que, aunque manifiesten preocupación sobre el tema, la población no incorpora significativamente acciones prácticas en su cotidianeidad, principalmente por un desconocimiento sobre esto.

Palabras clave: actitud, conciencia ambiental, impactos ambientales. 


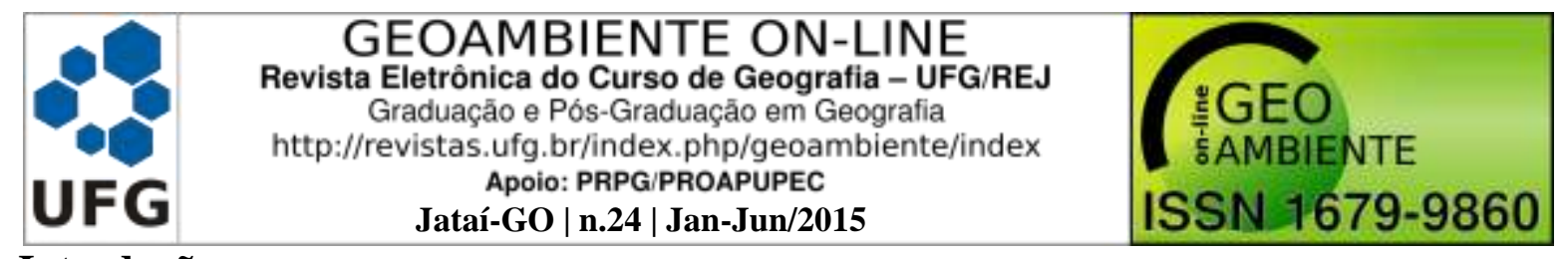

Introdução

Quando se fala sobre a utilização dos recursos naturais, percebe-se que nas últimas décadas houve um aumento da preocupação com seu uso de forma sustentável, pois a exploração descuidada do ambiente e a limitação de tais recursos trazem como consequência discussões que envolvem, inclusive, a própria sobrevivência da espécie humana. Marin e Lunelli (2010) apontam que se reconhece ao cidadão o direito de usufruir do ambiente que o cerca, da mesma forma que são impostos deveres, no sentido de se garantir a utilização racional dos recursos ambientais.

Segundo Filardi, Siqueira e Binotto (2011), as relações do homem com a natureza condizem com o próprio tempo de existência da humanidade, sendo que essas relações são caracterizadas por alterarem-se significativamente com o decorrer do tempo, condicionadas pelo processo de desenvolvimento a que o homem sempre esteve sujeito. Assim, com o tempo, ocorreu grande aumento do desperdício, da cultura descartável que, em um olhar simplista, conduziria a comodidade e o conforto, e isso tem trazido efeitos degradantes levando o planeta aos limites da insustentabilidade.

Visando um melhor entendimento dessas interações socioambientais, salienta-se que a partir da Revolução Industrial ocorreu um significativo aumento populacional, o qual acabou por ampliar os níveis de consumo e degradação ambiental que resultaram principalmente de valores e costumes ditados pelo sistema social e econômico consolidado a partir de então (ARRUDA et al., 2007).

No que tange a observação dos atuais padrões de consumo da população, evidencia-se que a crescente utilização de produtos com menores ciclos de vida e de embalagens descartáveis criados pela sociedade, tem sido responsáveis pela geração de uma grande quantidade de resíduos sólidos urbanos (RSU). Em consequência, os sistemas tradicionais de disposição final atingem mais facilmente o seu limite de capacidade, demonstrando a necessidade de se encontrar alternativas para a destinação final dos bens após seu consumo, para minimizar seu impacto ambiental (GOLÇALVES, TANAKA e AMENDOMAR, 2013).

Ainda segundo Gonçalves, Tanaka e Amendomar (2013), faz-se necessária a adoção de procedimentos de coleta seletiva e destinação final dos RSU gerados, pois sua importância relaciona-se a três fatores principais: a grande quantidade de resíduos gerada, os 


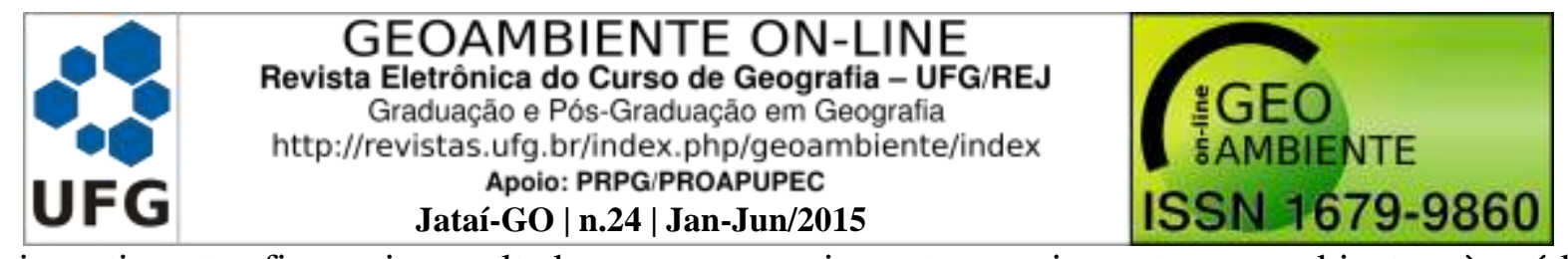

investimentos financeiros voltados a seu gerenciamento e os impactos ao ambiente e à saúde da população.

Com base nesses aspectos, em 2010 ocorreu a promulgação da lei $\mathrm{n}^{\circ}$ 12.305/2010, que instituiu a Política Nacional de Resíduos Sólidos (PNRS), que estabelece as condições e diretrizes para que estados e municípios elaborarem seus planos de resíduos sólidos. A lei define uma ordem de prioridade para a gestão de resíduos (que deixa de ser voluntária e passa a ser obrigatória): não geração, redução, reutilização, reciclagem, tratamento dos resíduos sólidos e disposição final ambientalmente adequada dos rejeitos (BRASIL, 2010).

Segundo Campos (2012), dados de 2009 demonstram uma massa coletada de resíduos sólidos domiciliares e públicos variando entre $0,77 \mathrm{~kg} / \mathrm{habitante}$ dia a $1,19 \mathrm{~kg} / \mathrm{habitante}$ dia, sendo a média dos valores de 0,96 kg/habitante.dia. Para a região de Lages $/ \mathrm{SC}$, o Plano Estadual de Gestão Integrada de Resíduos Sólidos (PEGIRS), elaborado em 2012, aponta uma geração de 125,38 toneladas/dia para uma população urbana de 153.937 habitantes, o que representa uma geração média per capita de $0,814 \mathrm{Kg} /$ habitante.dia

Nesse contexto torna-se importante a compreensão deste cenário, pela realização de estudos e trabalhos que permitem entender que a percepção ambiental humana constitui uma visão ímpar, uma vez que, a investigação e compreensão dos sentimentos e valores têm um papel importante para formação de juízos de valor e atitudes que orientam ações sobre estes espaços (COSTA e COLESANTI, 2011). Em paralelo, a Educação Ambiental traz consigo uma perspectiva de formação de um novo agir social, moral e ético, cuja proposta de desenvolvimento da temática seja sob a perspectiva da interdisciplinaridade na tentativa de melhor atingir seus objetivos (PEREIRA, 2014).

Pacheco e Silva (2006) salientam ainda que discutir o conceito de percepção ambiental não é somente uma questão de dizer quais das representações científicas parecem corresponder melhor à realidade, mas elucidar as perspectivas científicas, sociais ou políticas veiculadas através da utilização desse conceito.

Diante desta perspectiva, o objetivo do presente trabalho foi avaliar a percepção e o comportamento dos residentes quanto a alguns aspectos ambientais comumente vivenciados em suas rotinas de vida, mediante a utilização de questionários aplicados à população do município de Lages-SC. 


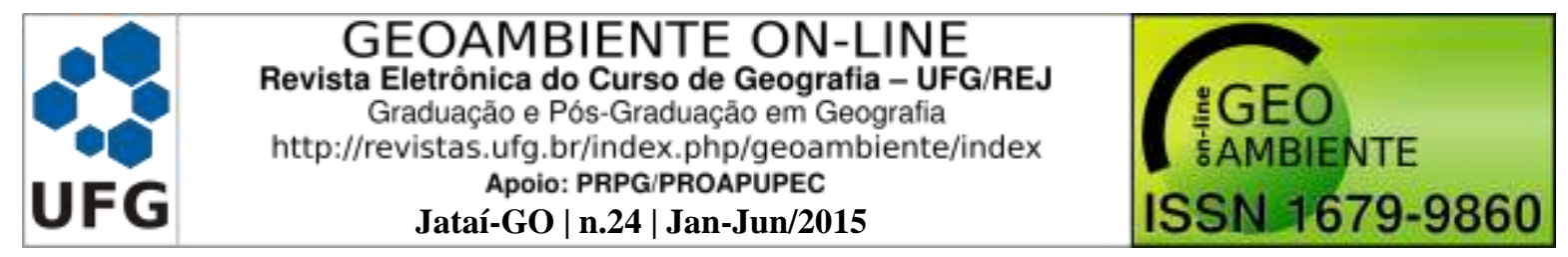

Metodologia

A área de abrangência da pesquisa situa-se no município de Lages/SC, situado no estado de Santa Catarina que, de acordo com o Censo Demográfico 2010 do IBGE (2010), possuía 156.727 habitantes residentes em 49.323 domicílios, dos quais mais de 98\% pertencem à área urbana, PIB per capita de R\$ 19.214,26 reais e o IDHM (Índice de Desenvolvimento Humano Municipal) de 0,77, caracterizando assim o universo da pesquisa.

A coleta de dados foi realizada por estudantes universitários do curso de Engenharia Ambiental, utilizando-se de um questionário semiestruturado, no período de agosto a dezembro de 2013. As variáveis de análise consideradas foram relacionadas a percepção do entrevistado quanto algumas questões ambientais, como também seu comportamento quanto ao destino dos resíduos sólidos produzidos em seu domicílio, destinação do óleo de cozinha, uso e destino da água e consumo de energia.

A pesquisa é exploratória e contemplou 89 domicílios, amostrados nos diferentes bairros do município de Lages, de forma aleatória e não probabilística. Com a finalidade de verificar possíveis diferenças nas respostas, também foi identificado o perfil dos entrevistados, considerando a escolaridade (ensino fundamental incompleto, ensino médio completo, ensino superior incompleto e ensino superior completo), o gênero (feminino ou masculino) e a idade.

\section{Resultados e discussão}

As relações entre a percepção e consciência ambiental dos entrevistados com o nível de escolaridade, o gênero (feminino ou masculino) e a idade (anos), são apresentados na Tabela 1. Os dados evidenciam que os entrevistados com maior nível de escolaridade apresentam maior preocupação ambiental quando comparados os de escolaridade menor.

No que se refere ao gênero, percebeu-se uma maior preocupação ambiental das mulheres, embora em algumas questões a situação seja oposta. Quanto as relações com a idade, visualizou-se um aumento da consciência ambiental com o aumento de idade para a maioria dos aspectos avaliados. 


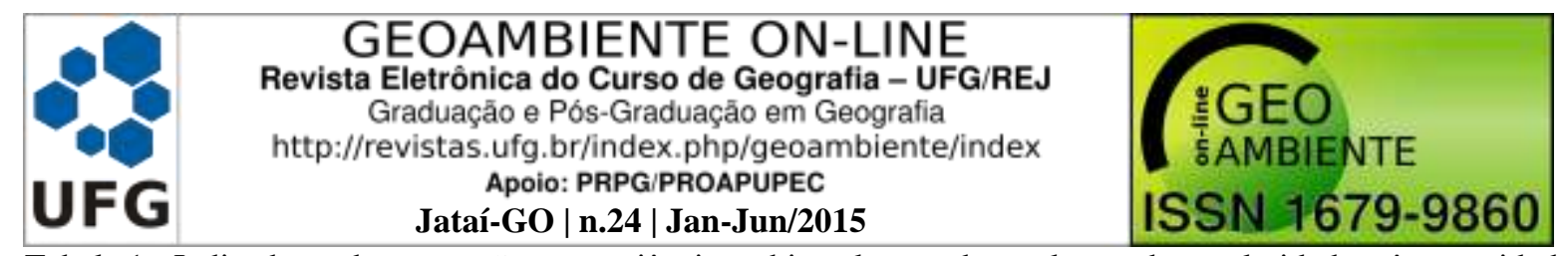

Tabela 1 - Indicadores de percepção e consciência ambiental segundo as classes de escolaridade, gênero e idade.

\begin{tabular}{|c|c|c|c|c|c|c|c|c|}
\hline \multirow[b]{2}{*}{ VARIÁVEIS } & \multicolumn{2}{|c|}{ Escolaridade } & \multicolumn{2}{|c|}{ Gênero } & \multicolumn{4}{|c|}{ Idade (anos) } \\
\hline & $\begin{array}{c}\text { EFI até } \\
\text { EMC }\end{array}$ & $\begin{array}{c}\text { ESI até } \\
\text { ESC }\end{array}$ & Masculino & Feminino & $\begin{array}{l}10 \\
\text { até } \\
18 \\
\end{array}$ & $\begin{array}{l}19 \\
\text { até } \\
24 \\
\end{array}$ & $\begin{array}{l}25 \\
\text { até } \\
49\end{array}$ & $\begin{array}{l}50 \\
\text { até } \\
85\end{array}$ \\
\hline Separa o lixo? & $51 \%$ & $61 \%$ & $42 \%$ & $67 \%$ & $38 \%$ & $43 \%$ & $69 \%$ & $71 \%$ \\
\hline $\begin{array}{l}\text { Conhece o problema do } \\
\text { óleo? }\end{array}$ & $67 \%$ & $89 \%$ & $74 \%$ & $80 \%$ & $50 \%$ & $86 \%$ & $76 \%$ & $79 \%$ \\
\hline $\begin{array}{l}\text { Existe destino correto do } \\
\text { esgoto na sua rua? }\end{array}$ & $33 \%$ & $61 \%$ & $42 \%$ & $51 \%$ & $25 \%$ & $57 \%$ & $40 \%$ & $43 \%$ \\
\hline $\begin{array}{l}\text { Se preocupa com o } \\
\text { desperdício de água? }\end{array}$ & $71 \%$ & $93 \%$ & $82 \%$ & $82 \%$ & $75 \%$ & $89 \%$ & $79 \%$ & $43 \%$ \\
\hline $\begin{array}{l}\text { Conhece o destino do lixo } \\
\text { de sua cidade? }\end{array}$ & $49 \%$ & $70 \%$ & $61 \%$ & $59 \%$ & $50 \%$ & $69 \%$ & $55 \%$ & $50 \%$ \\
\hline $\begin{array}{l}\text { Se preocupa com o } \\
\text { desperdício de energia } \\
\text { elétrica? }\end{array}$ & $82 \%$ & $93 \%$ & $79 \%$ & $94 \%$ & $88 \%$ & $83 \%$ & $91 \%$ & $93 \%$ \\
\hline $\begin{array}{l}\text { Tem o hábito de queimar o } \\
\text { lixo? }\end{array}$ & $24 \%$ & $2 \%$ & $13 \%$ & $14 \%$ & $25 \%$ & $11 \%$ & $6 \%$ & $29 \%$ \\
\hline
\end{tabular}

Nota: EFI = Ensino Fundamental Incompleto; EMC = Ensino Médio Completo; ESI = Ensino Superior Incompleto; ESC = Ensino Superior Completo

Chama-se atenção para o fato de que, os resultados apresentados na Tabela 1, revelam existir uma maior preocupação e percepção ambiental conforme o aumento do grau de escolaridade. Ou seja, a escolaridade das pessoas influencia diretamente em suas ações, pois quanto maior é acesso a informações, maior o grau de conhecimento e conscientização do cidadão.

Quanto ao gênero (feminino ou masculino), houve predominância, na maior parte dos casos, de atitudes e pensamentos ambientais mais corretos provenientes das mulheres, devendo-se muitas vezes ao fato de que são elas as responsáveis pelas atividades domésticas de suas residências, tais como a separação e destinação dos resíduos e reutilização de água.

No que se refere à idade, percebe-se a existência de que, com o aumento da idade, aumenta também a preocupação ambiental das pessoas. Porém, vale ressaltar que, em alguns casos, quando consideramos a faixa etária de 50 a 85 anos, a consciência ambiental pode ser diminuída devido ao fato de questões culturais e tradições trazidas consigo ao longo de suas vidas, já que a busca por atitudes ambientalmente corretas tem sido mais debatidas somente nas últimas décadas. Já entre as faixas de idade ligeiramente abaixo (de 19 até 24 anos e de 25 até 49 anos) o aumento gradativo das preocupações pode ser explicado pela introdução 


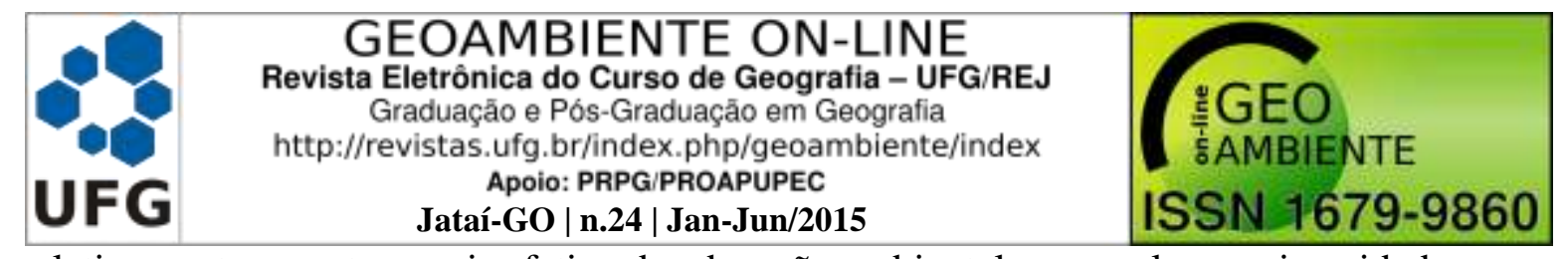

relativamente recente e mais efetiva da educação ambiental em escolas e universidades, o que, além da busca e acesso à maiores informações.

\section{Resíduos sólidos}

Com base na metodologia de estudo realizada em Lages-SC, buscou-se conhecer comportamento das pessoas relacionadas à geração, separação e destinação dos resíduos sólidos provenientes de suas diferentes formas de consumo. Quando questionadas se separavam ou não os resíduos para seu posterior descarte, $56,18 \%$ do total de entrevistados afirmaram separá-lo justificando tal atitude por acharem necessário, por facilitar a coleta ou pela preocupação com o meio ambiente. Já para 43,82\% que forneceram resposta negativa apontaram não realizar esta tarefa principalmente por não terem conhecimento da existência de coleta seletiva no município, não terem o hábito, falta de tempo ou não acharem importante.

Dentre os que afirmaram separar os resíduos, revelaram que o lixo reciclável obtido em sua separação é destinado: $25,84 \%$ para coleta comum; $25,84 \%$ para coleta seletiva da prefeitura; 5,62\% levam a pontos de reciclagem; 3,37\% entregam diretamente à catadores desses materiais; e 39,33\% não sabem ou não opinaram. Ainda relacionado a este tema, $87,64 \%$ dos abordados demonstraram preocupação com o lixo produzido enquanto transitam em vias públicas, guardando-os até encontrar uma lixeira ou levando-os para casa quando não encontram lixeiras próximas.

Um estudo realizado por Filardi, Siqueira e Binotto (2011) na serra catarinense apontou que os catadores entrevistados afirmam que o volume de lixo coletado, em $24 \%$ dos casos, de 100 a $500 \mathrm{~kg}$ ao mês; $48 \%$ de 500 a $1000 \mathrm{~kg}$; outros $24 \%$ de $1000 \mathrm{~kg}$ a $5000 \mathrm{~kg}$; e $5 \%$ coletam acima de $5000 \mathrm{~kg}$ de lixo ao mês. Os autores consideram que este volume é elevado, justificado pela realização de um trabalho conjunto entre os catadores.

Salienta-se ainda que 48,3\% dos indagados apontaram saber o destino dos resíduos sólidos de Lages-SC (aterro sanitário), 40,5\% disseram não saber o destino e 9,0\% responderam saber a destinação, porém disseram incorretamente ser este, o antigo lixão.

Sobre a geração e utilização de sacolas plásticas (Figura 1), os entrevistados foram questionados quanto ao modo como transportam suas compras, chegando-se às seguintes 


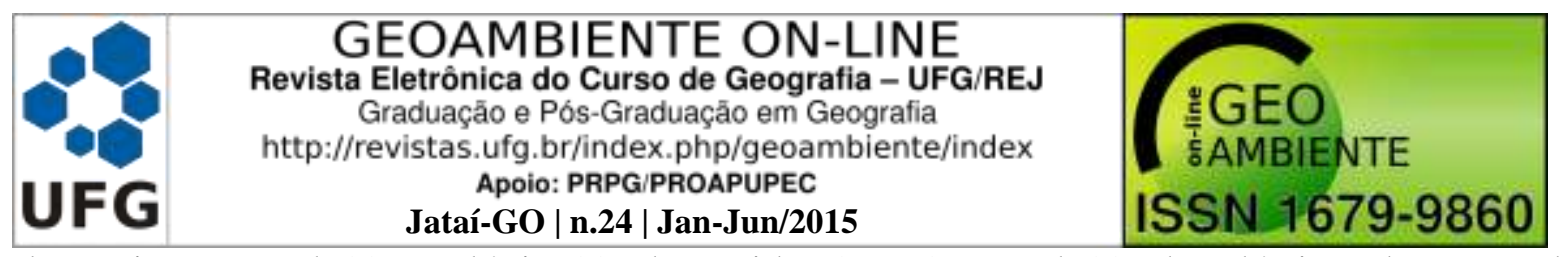

alternativas: sacola(s) ecológica(s) de tecido (7,9\%), sacola(s) de plástico do mercado (74,2\%), às vezes sacolas ecológicas e outras vezes sacolas de plástico do mercado $(6,7 \%)$, caixa(s) de papelão e às vezes sacolas ecológicas ou sacolas plásticas $(11,2 \%)$. Para os que utilizam sacola plástica ficou evidenciado que, após o uso das sacolas para o transporte das mercadorias, o principal destino da mesma é seu uso como saco de lixo.

Figura 1- Destino dado às sacolas plásticas obtidas nas compras de mercadorias.

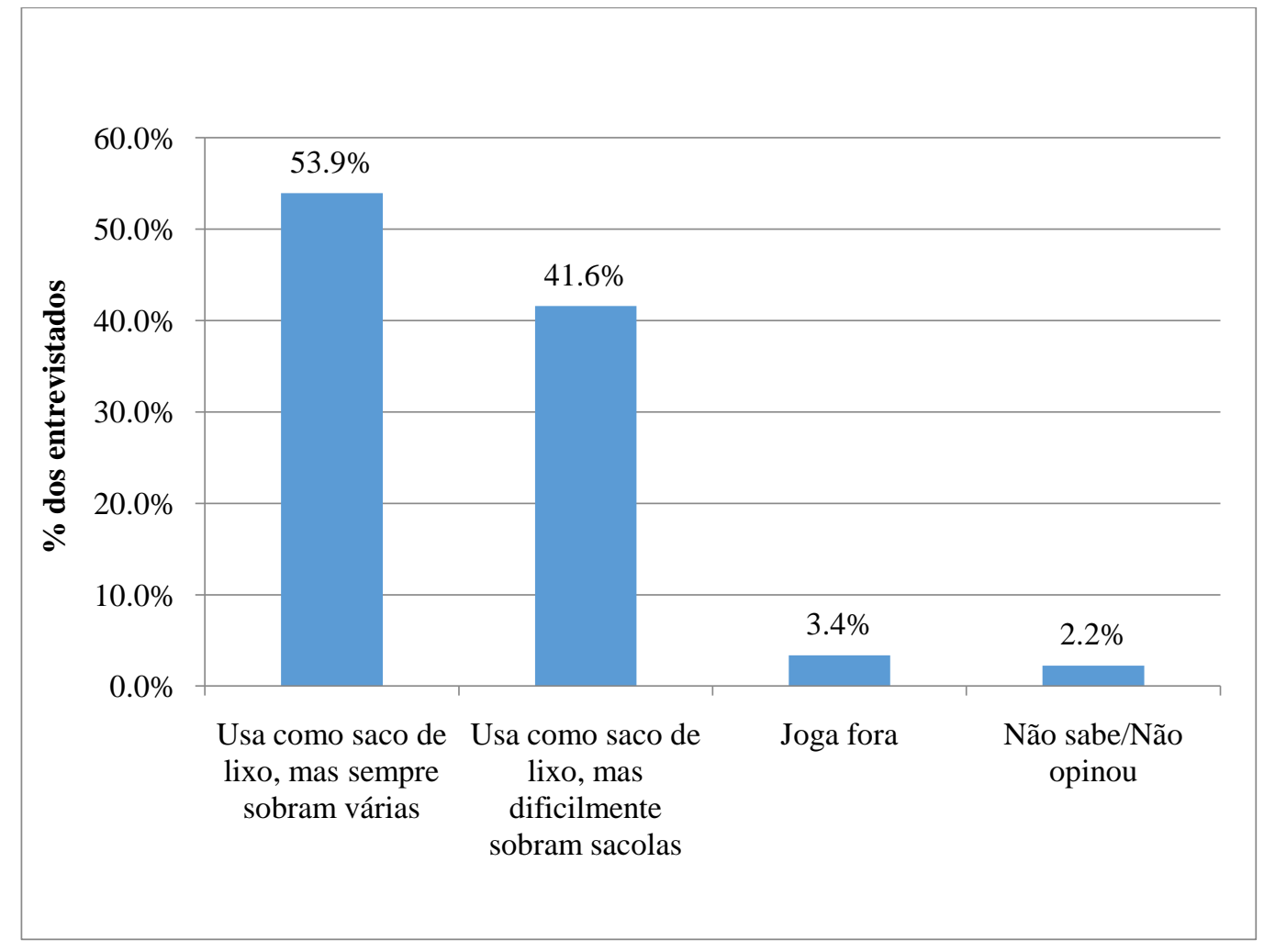

Fonte: Próprio autor, (2015)

Essa grande porcentagem do uso de sacolas plásticas pode ser referente a uma praticidade encontrada no seu uso, visto que, são achadas com facilidade no comércio além de, geralmente, não terem custo adicional. Enquanto que, as sacolas ecológicas e caixas de papelão precisam ser levadas pelos consumidores até o local, ou ainda, no caso das caixas de papelão podem ser fornecidas pelos estabelecimentos, mas depende-se da disponibilidade.

Quando questionados sobre a destinação dos eletrônicos inutilizados, os entrevistados apontaram dar os seguintes destinos: joga no lixo doméstico (30,3\%), separa e entrega em pontos de coleta $(30,3 \%)$, guarda em casa $(38,2 \%)$ e enterra $(1,1 \%)$. Considera-se que dentre os que responderam guardar em casa, fazem-no com um intuito posterior de, provavelmente, após armazenar uma quantidade significativa, proporcionar alguns dos demais destinos 


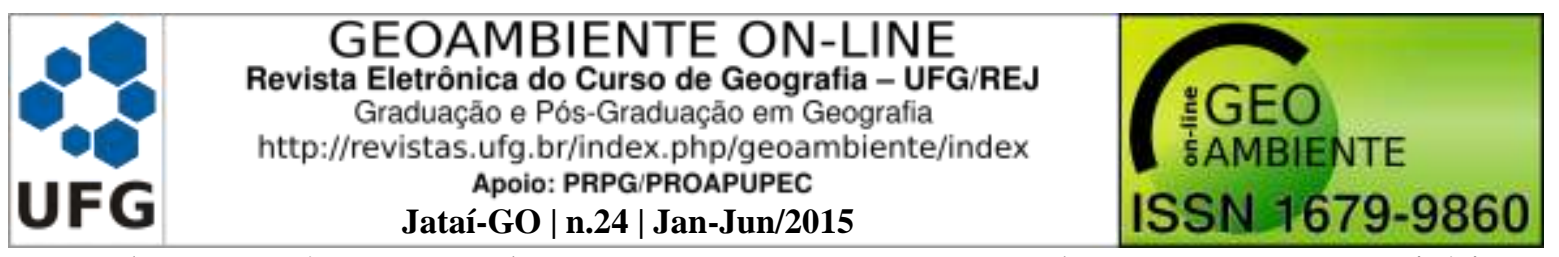

pontuados. Esta é uma grande preocupação, uma vez que chegam a aterros sanitários ou lixões, esses materiais podem resultar em graves consequências para os seres humanos, animais e ambiente, pois possuem diferentes substâncias e elementos químicos que podem ser nocivos à saúde, dentre os quais se destacam os metais pesados como o alumínio, o arsênio, o bário, o cobre e o chumbo (CEMPRE, 2007).

Já sobre a destinação de lâmpadas inutilizadas, várias foram as respostas fornecidas, dentre as quais as mais citadas foram o lixo comum e o armazenamento nos domicílios para posterior entrega a pontos de coleta. É relevante apontar que as lâmpadas possuem substâncias que podem ser agentes poluidores do meio, bem como provocar danos à saúde humana, não devendo, desta forma, serem descartadas no lixo comum. É importante e positivo que a população leve tais materiais a pontos especializados de coleta que providenciem sua destinação mais adequada.

Sabe-se que uma prática muito executada ainda é a queima domiciliar dos resíduos sólidos gerados. Sobre essa questão, os dados apontam que $13,5 \%$ das pessoas ainda exercem essa prática, queimando-os uma vez por semana ou sempre que necessário. Merece destaque que $25 \%$ dos entrevistados, na faixa etária de 10 a 18 anos, respondeu ter ou ver essa ação em suas rotinas, o que revela ainda, uma necessidade de atenção no que tange a periculosidade da execução desta tarefa nesta faixa etária. Além disso, também faz-se necessária uma maior conscientização referente aos poluentes que podem ser emitidos à atmosfera como resultado dessa queima.

\section{Óleo de cozinha}

Quando indagados sobre o conhecimento dos problemas causados pelo descarte do óleo de cozinha no esgoto comum, 22,5\% dos entrevistados revelaram ainda não saberem de tais consequências. Revelaram ainda que as principais formas de descarte deste resíduo em suas residências são o lixo comum (15), os pontos de coleta (27), produção de sabão (18), ralo da pia (16) ou ainda, em poucos casos, o despejo diretamente no solo (4), outras respostas (9).

Sabendo que o óleo de cozinha gerado em residências, comércio ou indústrias é potencialmente poluidor quando descartado de maneira inadequada, o Programa de Gestão Ambiental (PGA) (2012), do Ministério Público Federal, relata que para cada litro de óleo de 


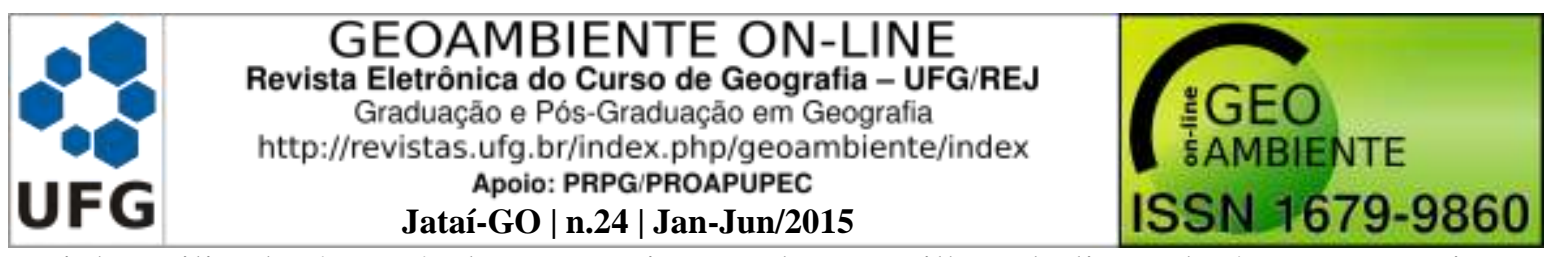

cozinha utilizado é possível a contaminação de um milhão de litros de água, que seriam suficientes para uma pessoa usar durante 14 anos (aproximadamente). Dentre os problemas possíveis está o fato de que o óleo impede a troca de oxigênio entre a água e a atmosfera acarretando na morte de seres vivos como plantas, peixes e microrganismos. Além disso, impermeabiliza o solo, contribuindo para as enchentes.

A destinação adequada deste resíduo deve seguir a cadeia de suprimentos reversa do óleo de cozinha que pode ser utilizado em uma ampla gama de produtos, tais como: rações animais; indústrias de cosméticos; indústrias de materiais de limpeza; indústrias de tintas; e indústria de biodiesel (ZUCATTO, WELLE e SILVA, 2013).

\section{Recursos hídricos e efluentes}

No presente estudo, $82,02 \%$ das pessoas abordadas afirmaram estarem preocupadas com o desperdício de água e entre estas, as medidas citadas para evitar o uso inadequado deste recurso foram o controle do tempo no banho, no escovar os dentes e ao lavar louça (Figura 2).

Figura 2 - Medidas adotadas pelos entrevistados visando minimizar o desperdício de água.

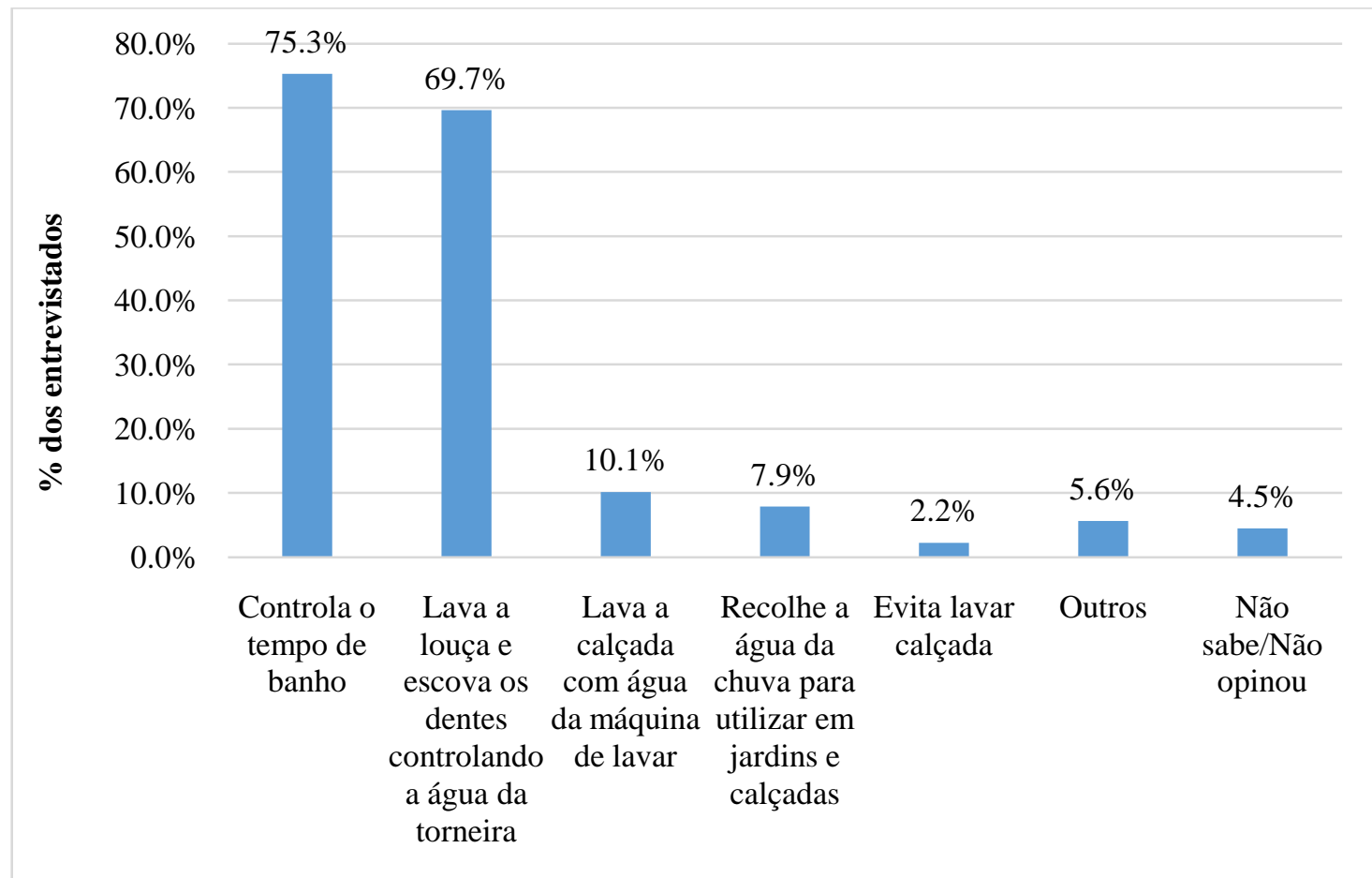

Fonte: Próprio autor, (2015) 


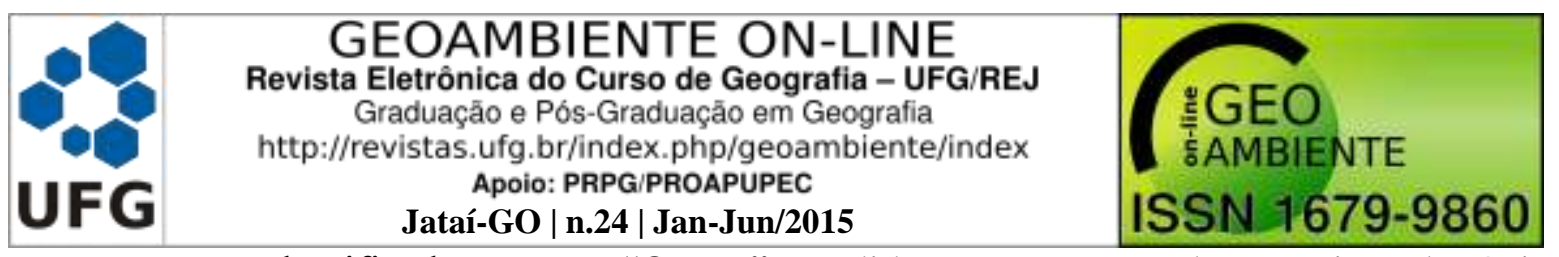

Foram classificadas como "Outras" medidas como: uso de torneira eletrônica, fechamento da torneira quando não está usando, evitar vazamentos, escovar os dentes com copo e lavar o carro com balde, que aparecem com $1,12 \%$ cada.

Quando se analisa o cenário hídrico, é possível pontuar que a vazão média anual dos rios brasileiros é de $179.000 \mathrm{~m} 3 / \mathrm{s}$ que, quando comparada a disponibilidade hídrica mundial de água doce superficial que é de 1,5 milhão de $\mathrm{m}^{3} / \mathrm{s}$, revela que o Brasil possui cerca de $13 \%$ da disponibilidade mundial demonstrando significativa importância de se voltar atenções a esta temática, visando sua preservação (BRASIL, 2006).

Sobre as enchentes ocorridas no município, os entrevistados puderam optar por uma ou mais alternativas que julgavam ser(em) a(s) causa(s) desse acontecimento (Figura 3), sendo que o lixo foi apontado como uma das principais causas, seguido do descaso dos órgãos públicos e da ocupação irregular.

Figura 3 - Respostas dos entrevistados sobre as principais causas das enchentes no município de Lages-SC.

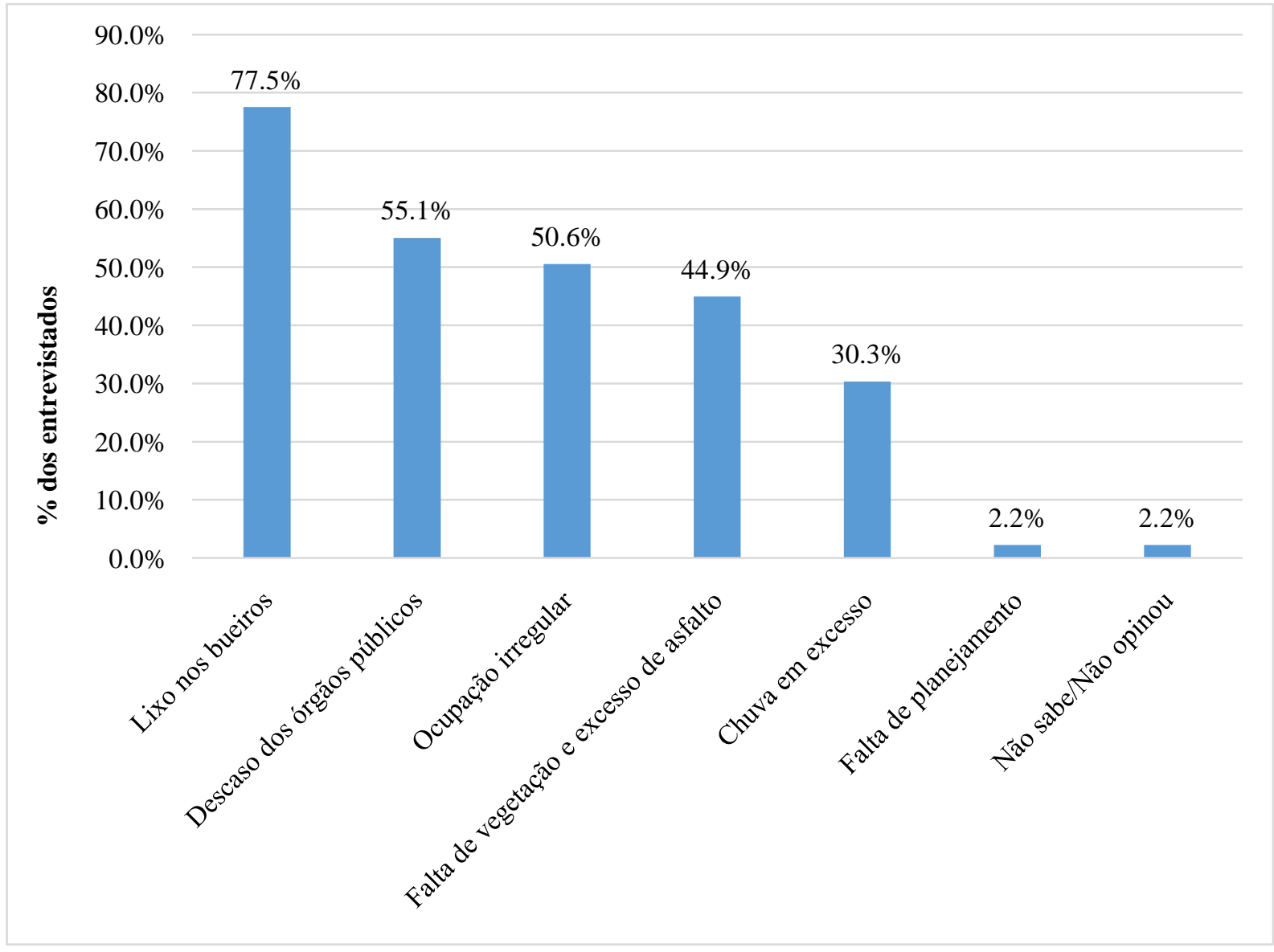

Fonte: Próprio autor, (2015) 


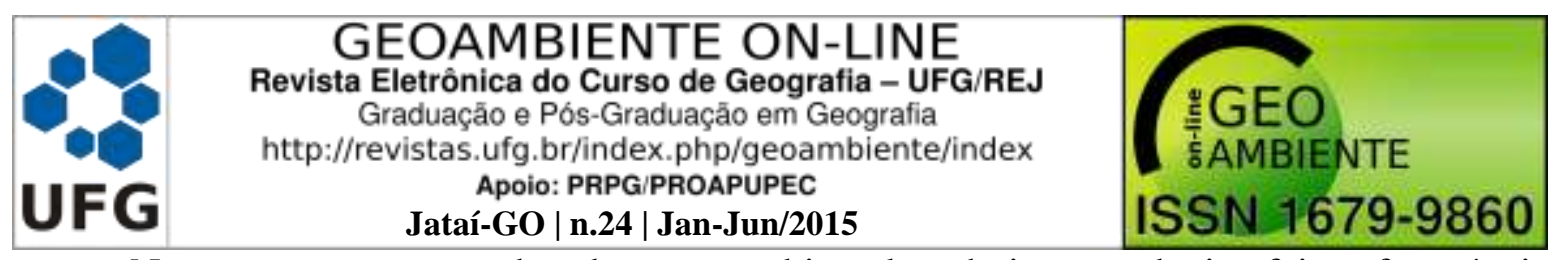

Neste aspecto, ações de educação ambiental poderiam produzir efeitos favoráveis à minimização de problemas como lixo nos bueiros e, em parte, atitudes de ocupação irregular (próximo a áreas de risco nas margens dos rios). A recuperação com as matas ciliares e um efetivo planejamento municipal seria, da mesma forma colaborativos.

Não somente o modo de uso da água deve ser analisado, mas sim o conhecimento da população sobre os perigos e destinação adequada dos efluentes gerados (esgoto). Os entrevistados foram submetidos à pergunta: "Existe destinação correta do esgoto na sua rua?" e as respostas apontaram que: $47,19 \%$ disseram "sim", $20,22 \%$ responderam "não" e $32,58 \%$ não soube/não opinou.

Esse dado demonstra que muitas pessoas ainda desconhecem a destinação do esgoto ou, ainda pior, não possuem uma destinação correta, necessitando assim, um maior engajamento dos órgãos públicos e da sociedade para que se conscientizassem da importância do saneamento básico na sua qualidade de vida.

Rodrigues e Batistela (2013) apontam que, para um adequado gerenciamento da utilização dos recursos hídricos no Brasil, faz-se necessário um equilíbrio entre os diferentes setores usuários da água, revelando a existência de conflitos no seu uso para a agricultura irrigada, geração de energia elétrica, navegação, abastecimento urbano, uso industrial, saneamento básico, pesca e lazer. Não somente referente ao seu uso, Silva Filho, Morais e Silva (2013) destacam também que um município que não possui abastecimento de água por meio de recursos hídricos que atendam as especificidades de qualidade (tratamento) e quantidade (armazenamento), torna-se mais vulnerável ao risco de doenças na população.

\section{Energia elétrica}

No enfoque energético, os entrevistados responderam, de uma forma geral, estarem preocupados com o desperdício de energia elétrica (88\%) e apontaram práticas de controle da iluminação como as principais medidas para evitar tal desperdício (Figura 4). 


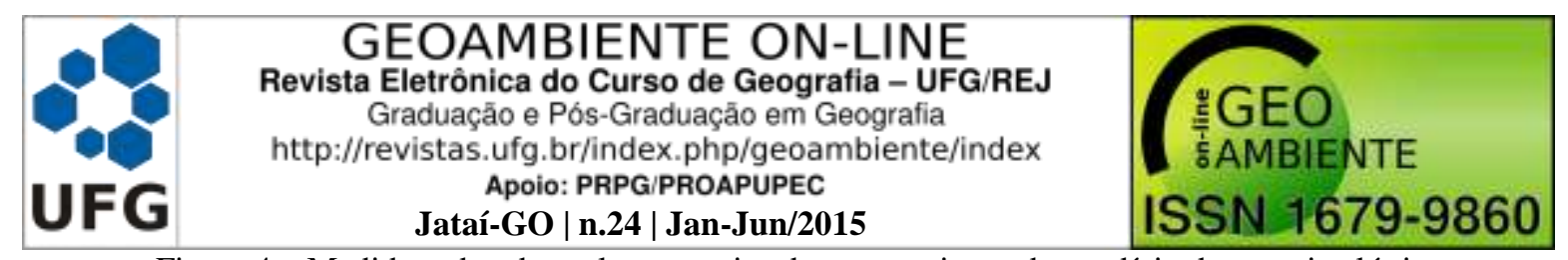

Figura 4 - Medidas adotadas pelos entrevistados para evitar o desperdício de energia elétrica.

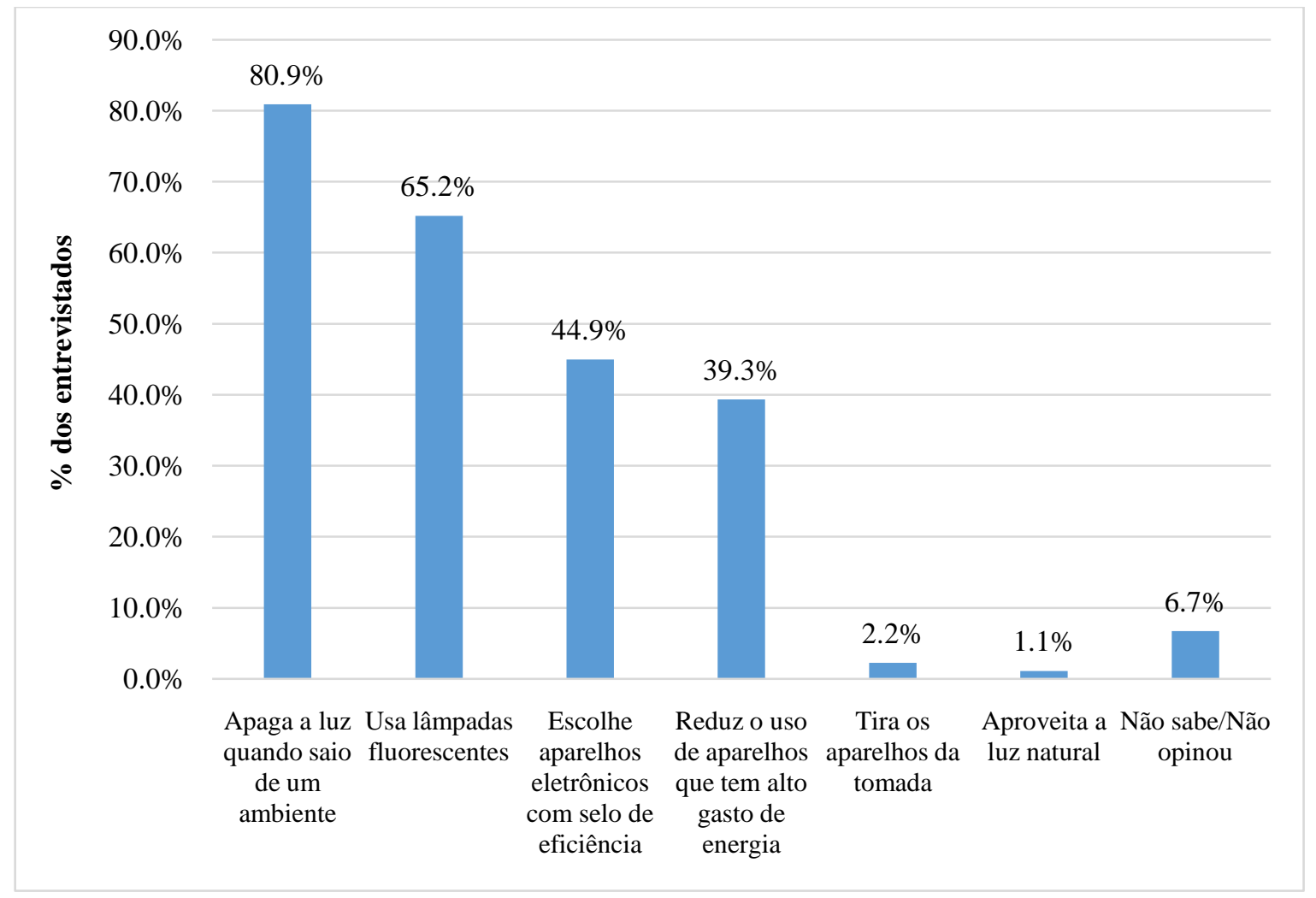

Fonte: Próprio autor, (2015)

Os dados apontam que a população tenta, através de ações possíveis em suas rotinas, diminuir desperdícios energéticos, porém, é preciso um maior esclarecimento de ações (não somente da sociedade, mas também de ordem pública e privada) que, quando somadas, podem potencializar ainda mais essa economia.

Segundo o Balanço Energético Nacional (BEN), no ano de 2013, houve uma demanda interna total de energia de 296,2 milhões de toneladas equivalentes de petróleo (MTep), o que representa um aumento de 4,5\% quando comparada à oferta energética do ano de 2012 (283,6 Mtep). Porém, desta energia disponibilizada, 260,2 MTep foram de fato consumidos, apontando uma perda de 36 MTep (EPE, 2014).

De acordo com Teixeira (2008), é possível perceber um padrão de consumo energético mais elevado em famílias com maior poder aquisitivo, relacionado ao maior número de eletrodomésticos em suas residências, sendo boa parte deles acionada por controle remoto e constantemente ligada, mesmo que no modo stand-by. 


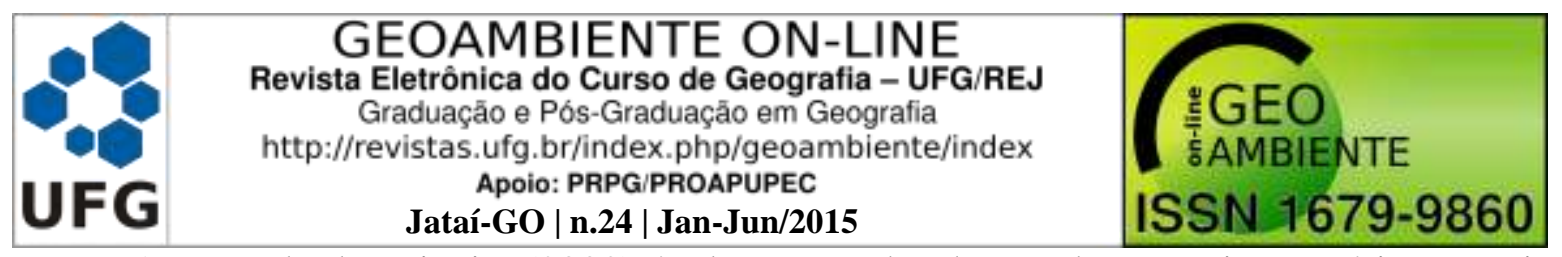

A exemplo de Teixeira (2008) é relevante a abordagem de que existem várias maneiras de promover a redução dos desperdícios de energia, podendo ser aqui citada a educação do consumidor, dentro ou fora da escola. Para o autor, por ser a escola um agente social importante, sua responsabilidade vai além do papel tradicional de apenas transmitir conhecimentos. Há atualmente, cada vez mais, uma complexidade vivenciada nas comunidades escolares (e consequentemente dos educadores) com desafios contemporâneos que visam potencializar temas que caracterizam-se como estratégias prósperas para a construção do conhecimento e da cidadania.

\section{Conclusões}

O levantamento de informações realizado no município de Lages/SC demonstrou que grande parte dos entrevistados adota práticas simples em suas residências que visam a redução do impacto ambiental. Contudo, ainda é necessário maior investimento em práticas de educação ambiental e ações de conscientização que contribuam para uma melhora conjunta a todos os aspectos ambientais, sejam eles relacionados a resíduos sólidos, recursos hídricos ou à poluição atmosférica.

Foi perceptível, também, que muitos assuntos ambientais como tratamento de esgoto, coleta seletiva e destinação de resíduos ainda são desconhecidos por boa parte das pessoas. Isso demonstra ser indispensável a criação, por exemplo, do Plano de Gerenciamento de Resíduos Sólidos com base na PNRS, que contemple projetos de divulgação das ações já praticadas na cidade, vinculando-as com possíveis ações colaborativas da sociedade em geral.

Os dados salientam ainda, que há uma preocupação e vontade de agir de forma colaborativa com as questões ambientais por parte dos moradores, porém, muitas vezes os mesmos não sabem exatamente quais ações e medidas devem tomar. Tal cenário, reforça a necessidade de uma educação ambiental realizada de modo interdisciplinar, abrangendo variadas áreas de conhecimento, de modo a adequar mais facilmente as atitudes ambientalmente corretas.

O trabalho contribui com informações para auxiliar a tomada de decisões por parte de gestores públicos, no sentido de implementar ações que visem a redução do impacto ambiental urbano. $\mathrm{O}$ estudo aponta ainda a necessidade de mais investimentos em pesquisas 


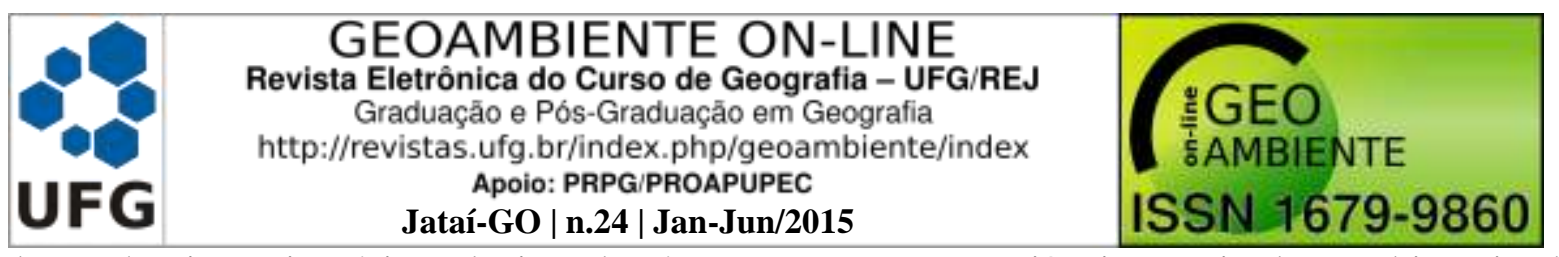

de cunho investigatório relacionadas às percepções, consciência e atitudes ambientais da população para possibilitar a criação de políticas públicas cada vez mais eficazes e condizentes com as necessidades locais.

\section{Referências Bibliográficas}

ARRUDA, L. N., PEREIRA, C. E.F., AFONSO, C. G., FERREIRA, M. P. L., LEITE, E.B., ABUHID, V. S. Aspectos relevantes na relação população $x$ meio ambiente. Sinapse Ambiental: Revista digital do curso de Ciências Biológicas: licenciatura e bacharelado em gestão ambiental, Betim: PUC Minas, v.4, n.2, 2007.

BRASIL, Política Nacional de Resíduos Sólidos. Lei No 12.305, de 2 de agosto 2010. 2010.

BRASIL. Plano Nacional de Recursos Hídricos. Ministério do Meio Ambiente. Programas nacionais e metas. Brasília, 2006. (Volume 4). Disponível em: <http://www.mma.gov.br/estruturas/161/_publicacao/161_publicacao03032011025031.pdf>. Acesso em: 11 de março de 2015.

CAMPOS, H. K. T. Renda e evolução da geração per capita de resíduos sólidos no Brasil. Engenharia Sanitária e Ambiental, v. 17, n. 2, p. 171-180, 2012.

CEMPRE - COMPROMISSO EMPRESARIAL PARA RECICLAGEM. Apresenta informações sobre reciclagem, 2007. Disponível em: <http://www.cempre.org.br>. Acesso em: 10 de abril de 2015.

COSTA, R. G. S.; COLESANTI, M. M. A contribuição da percepção ambiental nos estudos das áreas verdes. RA`E GA, Departamento de Geografia - UFPR, Curitiba, v. 22, p. 238-251, 2011.

EPE - EMPRESA DE PESQUISA ENERGÉTICA. Balanço energético nacional 2014 ano base 2013. Rio de Janeiro: EPE/MME, 2014.

FILARDI, F.; SIQUEIRA, E. S.; BINOTTO, E. Os catadores de resíduos e a responsabilidade socioambiental: a percepção sobre seu lugar social. Revista de Gestão Social e Ambiental - RGSA, São Paulo, v. 5, n. 3, p. 17-35, 2011. 


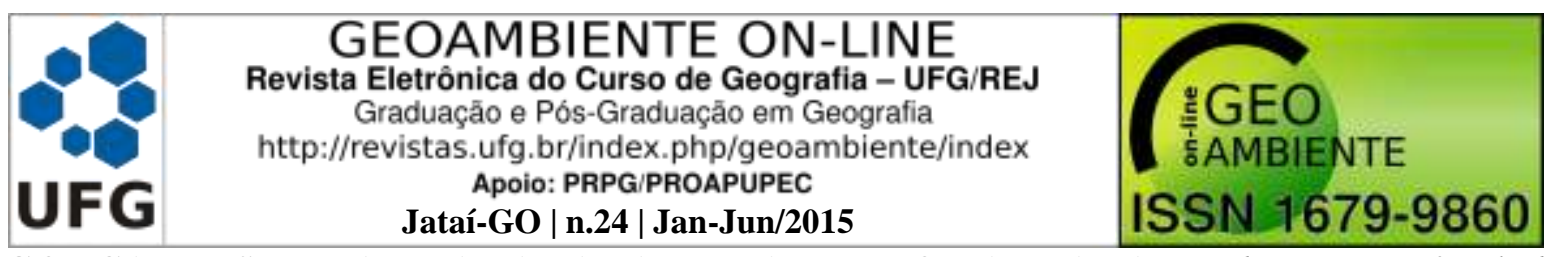

GONÇALVES, M. A.; TANAKA, A. K.; AMENDOMAR, A. A. A destinação final dos resíduos sólidos urbanos: alternativas para a cidade de São Paulo através de casos de sucesso. Future Studies Research Journal, São Paulo, v. 5, n. 1, p. 96-129, 2013.

INSTITUTO BRASILEIRO DE GEOGRAFIA E ESTATÍSTICA - IBGE. Censo Demográfico 2010. Disponível em: 〈http://cod.ibge.gov.br/233OG〉. IBGE, 2010. Acesso em: 10 de abril de 2015.

MARIN, J. D.; LUNELLI, C. A. Processo Ambiental, efetividade e as tutelas de urgência. Veredas do Direito, Belo Horizonte, v. 7, n.1 3/14, p. 311-330, 2010.

PACHECO, E.; SILVA, H. P. Compromissos epistemológicos do conceito de percepção ambiental. 2006. Disponível em: < http://www.ivt-rj.net/sapis/2006/pdf/EserPacheco.pdf>. Acesso em: 15 mai. 2009.

PEREIRA, F. A. Educação ambiental e interdisciplinaridade: avanços e retrocessos. Brazilian Geographical Journal: Geosciences and Humanities research medium, Ituiutaba, v. 5, n. 2, p. 575-594, 2014.

PLANO MUNICIPAL DE GESTÃO INTEGRADA DE RESÍDUOS SÓLIDOS. Estudo de regionalização da gestão integrada de resíduos sólidos do estado de Santa Catarina. Disponível em: <http://www.pmgirsamerios.com.br/amerios/download/residuos\%20solidos/PLANO\%20EST ADUAL\%20DE\%20GEST\%C3\%830\%20INTEGRADA\%20DE\%20RES\%C3\%8DDUOS\% 20S\%C3\%93LIDOS_2012.pdf >. Acesso em: 10 de março de 2015.

PROGRAMA DE GESTÃO AMBIENTAL - PGA. Sabão feito com óleo de cozinha: uma forma de diminuir o efeito estufa e a contaminação das águas. 2012. Disponível em: $<$ http://pga.pgr.mpf.mp.br/praticas-sustentaveis/sabao/sabao-feito-com-oleo-de-cozinha/?sear chterm=sab\%C3\%A3o $>$. Acesso em: 12 de abril de 2015.

RODRIGUES, M. L., MALHEIROS, T. F., FERNANDES, V., DARÓS T. D. A percepção ambiental como instrumento de apoio na gestão e na formulação de políticas públicas ambientais. Revista de Saúde Social, São Paulo, v. 21, supl.3, p. 96-110, 2012. 


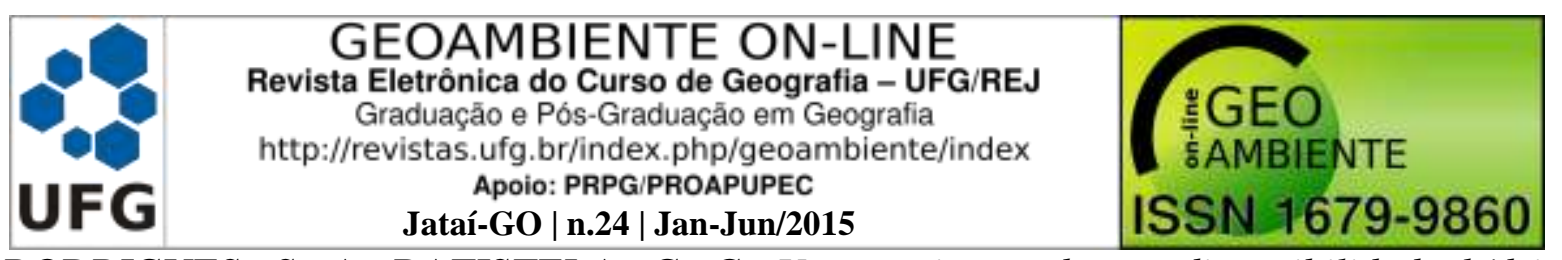

RODRIGUES, S. A; BATISTELA, G. C. Uma revisão sobre a disponibilidade hídrica brasileira para geração de energia elétrica. Geoambiente On-line: Revista Eletrônica do curso de Geografia do Campus Jataí, Jataí - GO, n.21, p. 48-67, 2013.

SILVA FILHO, A. C.; MORAIS, R. D. de; SILVA, J. B. da. Doenças de veiculação hídrica: dados epidemiológicos, condições de abastecimento e armazenamento da água em Massaranduba/PB. Geoambiente On-line: Revista Eletrônica do curso de Geografia do Campus Jataí, Jataí - GO, n. 20, p. 83-96, 2013.

TEIXEIRA, R. C. Desenvolvimento de tecnologia educacional para o uso racional de energia. Guaratinguetá, 220p. Tese (Doutorado em Engenharia Mecânica) - Faculdade de Engenharia, Campus de Guaratinguetá, Universidade Estadual Paulista, 2008.

ZUCATTO, L. C.; WELlE, I.; SILVA, T. N. da. Cadeia reversa do óleo de cozinha: coordenação, estrutura e aspectos relacionais. Revista de Administração de Empresas, São Paulo, v. 53, n. 5, p. 442-453, 2013. 